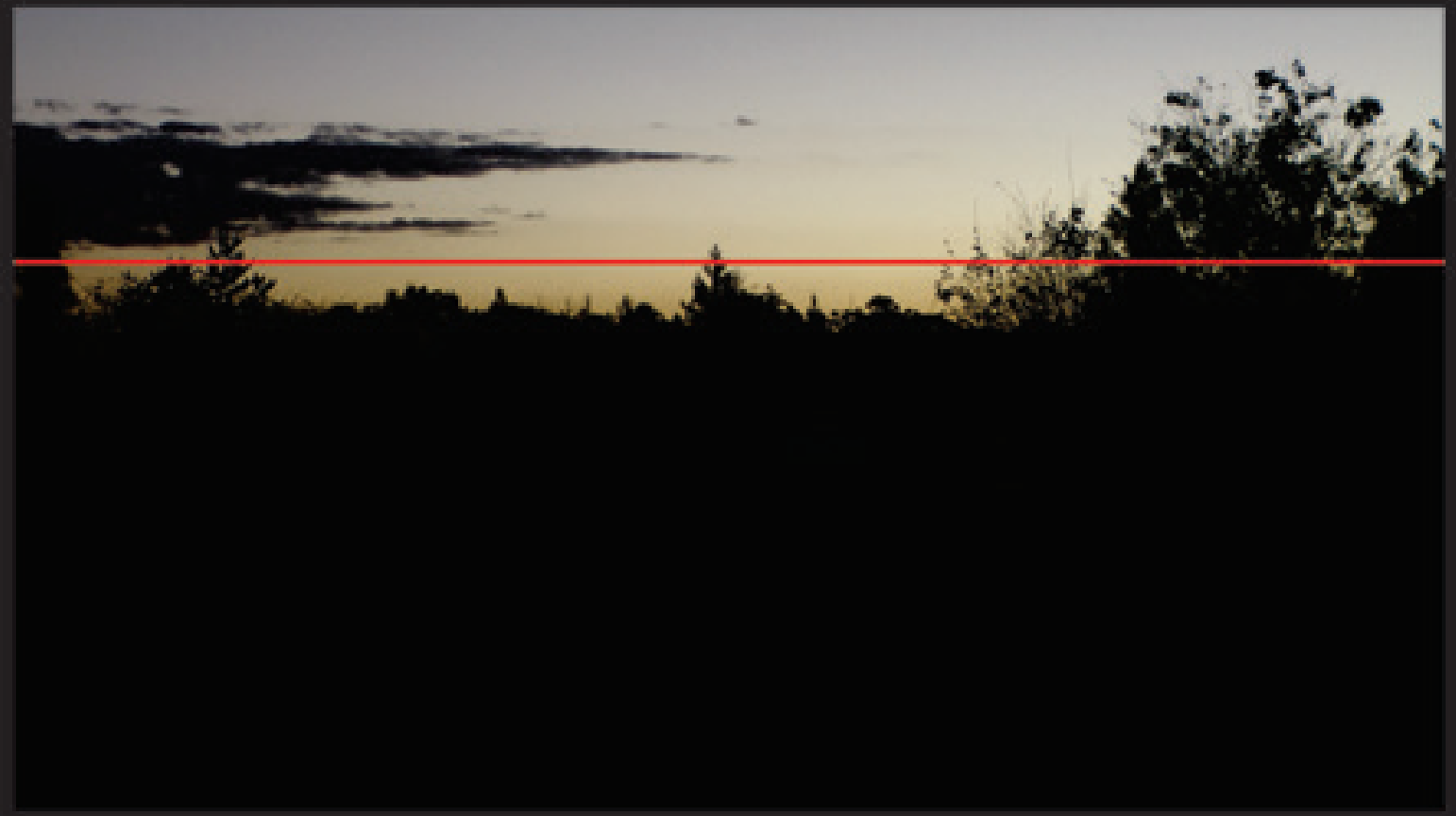




\section{O turismo na visão dos moradores de uma comunidade garimpeira: o caso de Extração (Curralinho), Diamantina, Minas Gerais}

Tourism in view of the residents of a goldmining community: the case Extração (Curralinho), Diamantina, Minas Gerais

Eveline Rosario Santos ${ }^{1}$ Hugo Rodrigues Araujo ${ }^{2}$

1 Bacharel em Ciências Humanas e do Turismo pela Universidade Federal do Vale do Jequitinhonha e Mucuri (UFVJM), Diamantina, MG.

2 Docente do curso de Turismo da Universidade Federal do Vale do Jequitinhonha e Mucuri (UFVJM), Diamantina, MG. 


\title{
Resumo
}

O presente estudo teve por objetivo analisar as implicações da atividade turística no Distrito de Extração (Diamantina, Minas Gerais), popularmente conhecido como Curralinho, a partir da percepção dos moradores locais. A pesquisa foi realizada por meio de revisão bibliográfica, análise documental, observação direta da comunidade em períodos distintos e entrevistas dos moradores utilizando questionário semiestruturado. Os resultados obtidos demonstram a necessidade de capacitação e qualificação dos moradores locais para o melhor aproveitamento dos benefícios que podem ser gerados para comunidade através do turismo. Espera-se que esse estudo subsidie intervenções do poder público e da iniciativa privada, com o intuito de se criar um planejamento turístico adequado a realidade local, considerando as percepções e participação dos moradores em todo o processo de desenvolvimento do turismo.

Palavras-chave: Turismo. Percepção. Desenvolvimento local.

\begin{abstract}
The present study aimed to analyze the implications of tourism in the District of Extração (Diamantina, Minas Gerais), commonly known as Curralinho, from the perception of local residents. The survey was conducted through literature review, document analysis, direct observation of the community in different periods and interviews of residents using semi-structured questionnaire. The results demonstrate the need for training and qualification of the locals for the best use of the benefits that can be generated for the community through tourism. It is hoped that this study will subsidize intervention by public authorities and the private sector in order to create a proper tourism planning at the local reality, considering the perceptions and participation of residents in the process of tourism development.
\end{abstract}

Keywords: Tourism. Perception. Local development..

\section{Introdução}

O turismo é hoje uma das maiores atividades econômicas do mundo. É um setor que tende a crescer 7,5\% ao ano nos próximos 10 anos, movimenta cerca de US\$3,4 trilhões (10,9\% do PIB mundial) e emprega 204 milhões de pessoas (10\% da força de trabalho global) (PANOSSO NETTO \& TRIGO, 2009). O turismo comprovadamente pode gerar inúmeros benefícios para os destinos, tais como: diversificar a economia, gerar empregos e renda, promover a preservação ambiental, melhorar a infraestrutura básica e, consequentemente, a qualidade de vida local (RUSCHMANN, 2000).

Diante dessa constatação, nos últimos anos o governo brasileiro, em todas as suas esferas (federal, estadual e municipal), passou a estimular o desenvolvimento do turismo 
em comunidades localizadas em regiões que apresentam raras belezas da natureza, assim como, tradições culturais peculiares. De acordo com o Ministério do Turismo, essa é uma forma de contribuir para a diversificação da oferta turística brasileira, associada ao desenvolvimento local com a geração de trabalho e renda (BRASIL, 2010).

Entretanto, há vários autores que, por meio de seus estudos, demonstraram que o desdobramento do turismo, principalmente em pequenas comunidades, deve considerar as potencialidades e desafios para o desenvolvimento local com base em uma análise minuciosa dos reflexos que podem ocorrer nas dimensões sociais, culturais, econômicas e ambientais (RUSCHMANN, 2000). Soma-se a isso, a importância de propiciar a inclusão da comunidade local em todas as fases de planejamento e implantação das atividades (VIGNATI, 2008). Esta é uma premissa fundamental baseada, principalmente, na proposição de associar o desenvolvimento do turismo à redução das desigualdades sociais e a melhoria da qualidade de vida dos moradores locais (PANOSSO NETTO \& TRIGO, 2009).

O desenvolvimento local através do turismo corresponde na oportunidade de inserção de atores sociais e econômicos na organização da oferta de produtos e serviços do destino. “Nesta perspectiva, indivíduos de uma comunidade se reúnem para buscar alternativas de sobrevivência econômica por meio da atividade turística, aliadas a outros fatores como a valorização do modo de vida local e a defesa do meio ambiente" (BRASIL, 2010, p. 11).

Embora essa teoria venha há algum tempo sendo enfatizada nas obras de referência sobre planejamento turístico, tem se tornado cada vez mais comum observar moradores de pequenas comunidades serem forçados a aceitar e conviver com a invasão de pessoas estranhas que surgem na localidade sem dar explicações e em proporções cada vez maiores. Esses "intrusos", inevitavelmente, provocam sérias mudanças no modo de vida tradicional e, muitas das vezes, causam impactos irreversíveis ao patrimônio local.

Trabalhar essas questões exige uma postura diferenciada no que se refere aos conteúdos e métodos de planejamento. Para que o turismo possa realmente contribuir com o desenvolvimento local, inicialmente, é preciso que a comunidade tenha conhecimento dos impactos que podem ser provocados, tanto positivos como negativos, e concordem que ele seja desenvolvido (VIGNATI, 2008; RUSCHMANN, 2000).

Diante disso, o presente estudo teve por objetivo analisar a percepção dos moradores de Extração, distrito de Diamantina, Minas Gerais, a respeito do turismo e suas implicações para a comunidade local. Essa investigação correspondeu ao trabalho de conclusão de curso do autor principal, sob a orientação do segundo autor.

A escolha de Extração, popularmente conhecido como Curralinho, como objeto de estudo dessa pesquisa foi determinada pelas suas características geográficas, culturais, 
naturais e econômicas. A área urbana do distrito possui 227 moradores e está localizada a 10 quilômetros do centro-histórico de Diamantina, tombado como Patrimônio Cultural da Humanidade pela UNESCO. Durante anos, as mineradoras exploraram de forma exacerbada o potencial diamantífero da região, e com a estagnação dessa atividade extrativista no fim do século passado não restaram muitas perspectivas para a população local, o que resultou na completa estagnação socioeconômica de Curralinho. Contudo, ainda encontra-se relativamente conservado o encantador núcleo paisagístico urbano da comunidade, constituído de singelas construções que remetem a tempos remotos. Além disso, bem próximo ao núcleo urbano existem atrativos naturais de grande beleza, como a Gruta do Salitre. Esses e outros fatores contribuíram para que nos últimos surgisse um fluxo crescente de visitantes na comunidade.

Entretanto, como em grande parte das pequenas localidades onde o turismo vem se desenvolvendo, observa-se que os moradores locais não têm a dimensão real do potencial turístico da comunidade e, ao mesmo tempo, não compreendem como podem se beneficiar da atividade sem afetar os hábitos e a cultura local.

Sendo assim, a realização deste trabalho justificou-se pela ausência de informações em relação ao turismo de Extração, com base na percepção dos moradores locais. $\mathrm{O}$ intuito principal foi verificar se a atividade turística tem realmente colaborado para melhoria da qualidade de vida da comunidade e promovido a inclusão social.

Para isso, foram realizadas visitas ao distrito de Extração com o intuito no primeiro momento de observar a relação dos moradores com os turistas e, no segundo momento, entrevistá-los para avaliar o conhecimento a respeito do turismo, bem como saber a opinião sobre os impactos positivos e negativos causados pela atividade turística na comunidade.

Conforme era esperado pelos autores, os resultados obtidos permitem questionar se realmente o turismo tem colaborado para o desenvolvimento local. Espera-se que a discussão iniciada nesse estudo possa subsidiar novas pesquisas e contribuir para elaboração de políticas públicas adequadas aos interesses e expectativas da comunidade.

\section{Materiais e métodos}

Para a efetivação deste trabalho buscou-se, inicialmente, a familiarização com a área de estudo, no caso a comunidade de Extração, por meio de pesquisa bibliográfica e documental. Foram consultados órgãos da Prefeitura Municipal de Diamantina, como a Secretaria de Cultura, Turismo e Patrimônio (SECTUR), o website do Instituto Brasileiro de Geografia e Estatística (IBGE), e diversas outras fontes. O objetivo dessa etapa foi levantar dados estatísticos sobre a população local, conhecer a origem e evolução da comunidade, e obter informações relacionadas ao turismo. 
Em seguida, deu-se início a pesquisa de campo com o intuito de coletar dados, por meio da observação direta e entrevista dos moradores locais. Primeiramente, visitou-se a comunidade em finais de semana aleatórios para observar os hábitos da comunidade e a forma com que os moradores locais se relacionavam com os visitantes.

Durante essa etapa, foram levantados os seguintes questionamentos:

- Quais as atividades os turistas praticam durante sua visita a Curralinho?

- Qual a relação dos visitantes com os moradores locais? Há interação entre esses dois públicos? Como ela ocorre?

- Os possíveis impactos positivos e negativos gerados pelo turismo na comunidade?

Com base em tais questionamentos elaborou-se um questionário contendo perguntas abertas e fechadas para entrevistar os moradores. A primeira parte do questionário tinha por objetivo identificar o perfil socioeconômico do entrevistado. A segunda parte, destinou-se a analisar a percepção sobre o turismo, e a opinião sobre os benefícios e malefícios para a comunidade. Por fim, procurou-se identificar o grau de envolvimento dos entrevistados com a atividade turística e o interesse de participar do processo de desenvolvimento do turismo na comunidade.

Atualmente, no núcleo urbano de Curralinho existem 128 domicílios particulares e coletivos (IBGE, 2010). Por ser uma comunidade relativamente pequena, buscou-se visitar todos os domicílios do núcleo urbano com o intuito de entrevistar o morador responsável, ou outro residente com idade mínima de 18 anos. No total, foram entrevistados 42 moradores de domicílios distintos. Os demais domicílios encontravam-se fechados, vagos, ou são de uso-ocasional.

Concluída a etapa das entrevistas, os questionários foram tabulados e os resultados analisados por meio do programa Microsoft Excel, com base no referencial teórico desse trabalho. Cabe aqui ressaltar que o estreito vínculo do autor principal com Curralinho permitiu que fosse mantido o olhar atento na relação dos moradores locais com os turistas, mesmo após a realização da pesquisa de campo, o que contribui muito com a análise dos resultados.

\section{O distrito de Extração (Curralinho)}

O distrito de Extração está situado a 10 quilômetros do centro histórico de Diamantina, tombado como Patrimônio Mundial da Humanidade pela UNESCO. $\mathrm{O}$ acesso ao distrito é realizado pela estrada municipal que faz ligação do trecho Diamantina-Extração. Esse trecho não é pavimento, mas está relativamente em boas condições de conservação e trafegabilidade (Figura 1). 

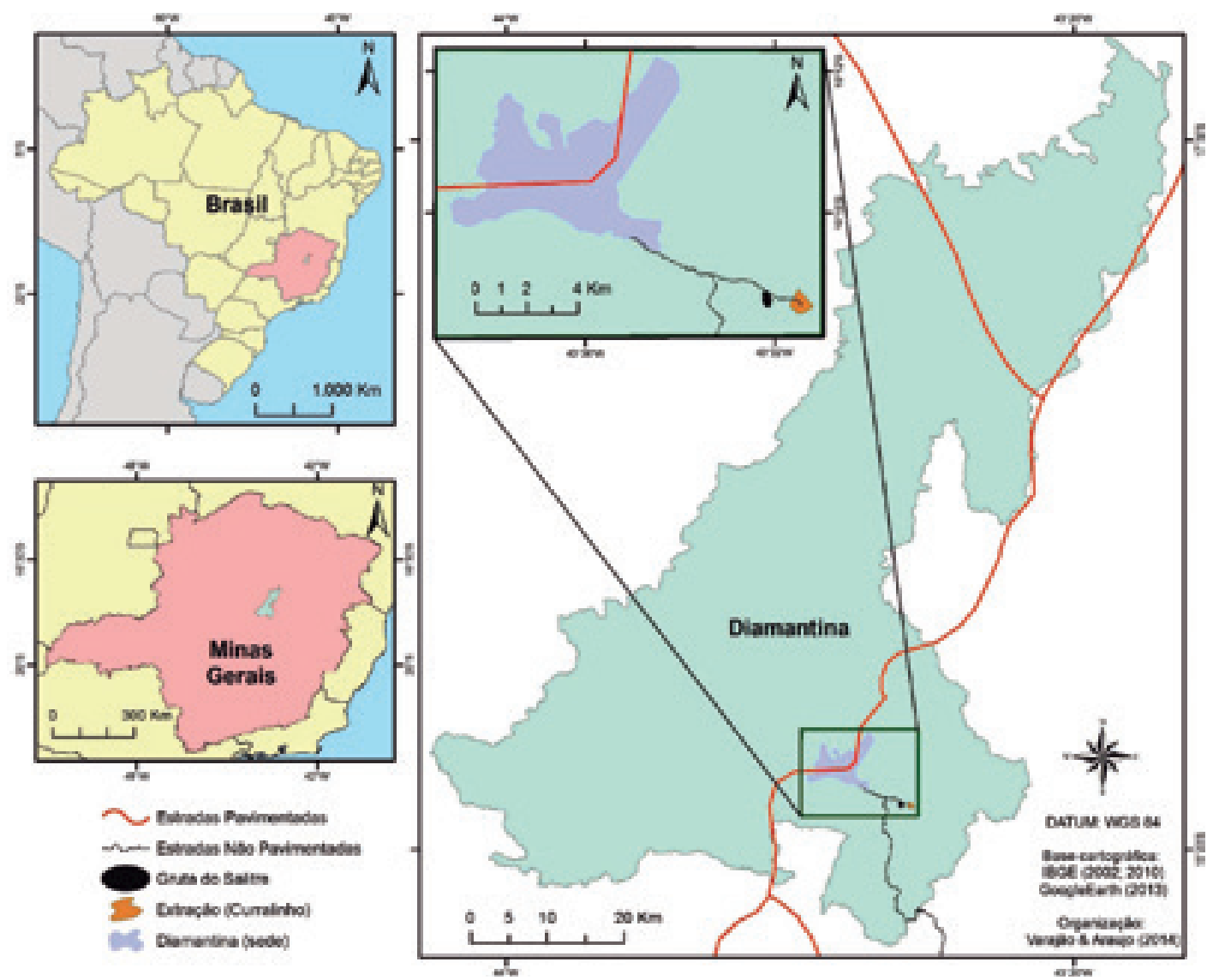

Figura 1. Mapa da localização de Extração (Curralinho) no município, no Estado e no país.

Fonte: ARAUJO (2014)

Suas origens remontam ao início do século XVIII, quando da ocupação dessa área por milhares de escravos que trabalhavam no leito dos cursos de água da região, inicialmente a serviço dos contratadores de diamantes e, posteriormente, pela Coroa Portuguesa que instituiu a Real Extração, em 1771. A localidade era conhecida originalmente por Curralinho, em função de um cercado para animais que ali existiu, do qual não se tem nenhum vestígio. Recebeu o nome atual "Extração" em 07 de setembro de 1932, através da lei no 843, porém popularmente continua sendo denominada como Curralinho (DIAMANTINA, 2004).

Por estar estrategicamente inserido na rota da "Estrada Real", o distrito de Curralinho foi, por muitos anos, ponto de parada de tropeiros que trafegavam pela região. As mercadorias vindas de Ouro Preto e do Rio de Janeiro passavam primeiramente pelo Distrito e, em consequência disso, a estrutura de comércio era bem mais intensa do que em Diamantina, em relação a qualidade e preço (PLANO DE INVENTÁRIO DE DIAMANTINA, 2010). 
No século $\mathrm{XX}$ as mineradoras exploraram de forma exacerbada o potencial diamantífero da região e, com a queda dessa atividade extrativista, não restaram perspectivas para as futuras gerações. Alguns ainda insistem em manter a tradição garimpeira, entretanto, a maioria da população local está desempregada ou trabaIhando em Diamantina (HERKENHOFF \& BORGES 2009). Atualmente, as atividades econômicas desenvolvidas no distrito concentram-se no setor primário representado pelo garimpo e a agricultura familiar, e o setor terciário composto, basicamente, de duas pousadas, três bares, um restaurante e uma mercearia.

Curralinho encanta pela beleza paisagística, pela riqueza cultural e simplicidade de seus moradores. O cenário da comunidade ainda transporta o visitante aos tempos passados de exploração da colônia, razão pelo qual já foi palco de grandes produções artísticas (Figura 2). Na década de 70, por exemplo, a comunidade serviu de cenário para o filme "Xica da Silva" de Carlos Diegues. Em 1995, foi escolhida pela Rede Globo como cenário principal da novela "Irmãos Coragem" transformando-se na cidade fictícia de Coroado/GO. Além disso, o filme "Vida de Menina" de Helena Solberg, baseado no livro-diário "Minha Vida de Menina - O Diário de Helena Morley", escrito por Alice Dayrell que viveu a infância em Diamantina, também teve cenas gravadas em Curralinho (DIAMANTINA, 2004).

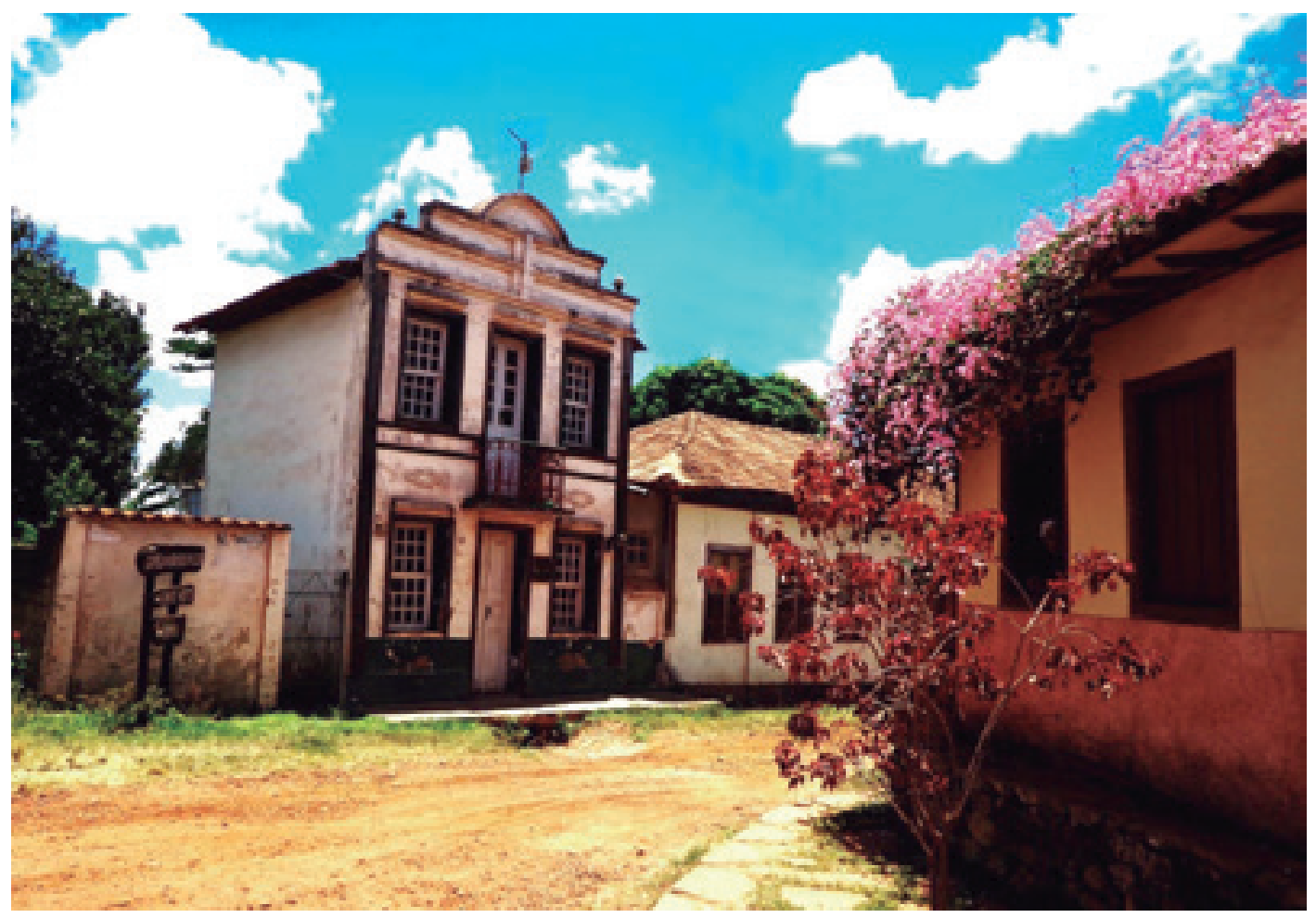

Figura 2. Distrito de Extração (Curralinho)

Fonte: Eveline R. Santos, 2014. 
Dentre os principais atrativos da comunidade está a Barragem de Curralinho construída em meados de 1950 pelas companhias de garimpo que exploravam as lavras de diamantes no alto da serra. A represa foi doada aos moradores e hoje é reconhecida como patrimônio da comunidade de Extração. Nos dias ensolarados esse atrativo costuma ser frequentado por moradores da região que vão em busca de banhos refrescantes (MINAS GERAIS, 2002).

A Gruta do Salitre está localizada a 1 quilômetro do centro de Curralinho é um dos atrativos naturais mais conhecidos de toda região. A cavidade se destaca por apresentar uma belíssima paisagem formada por rochas quartzíticas que se assemelham a um castelo medieval ou a uma igreja construída no estilo gótico (Figura 3). O local é amplamente visitado por pessoas que buscam lazer em contato com a natureza e, também, praticar esportes verticais como escalada e rapel. Desde 2010, a gruta se encontra sob a gestão do Instituto Biotrópicos - Organização não Governamental de caráter científico e socioambiental - e conta com uma infraestrutura básica para atendimento ao turista (AZEVEDO e ARAUJO, 2011).

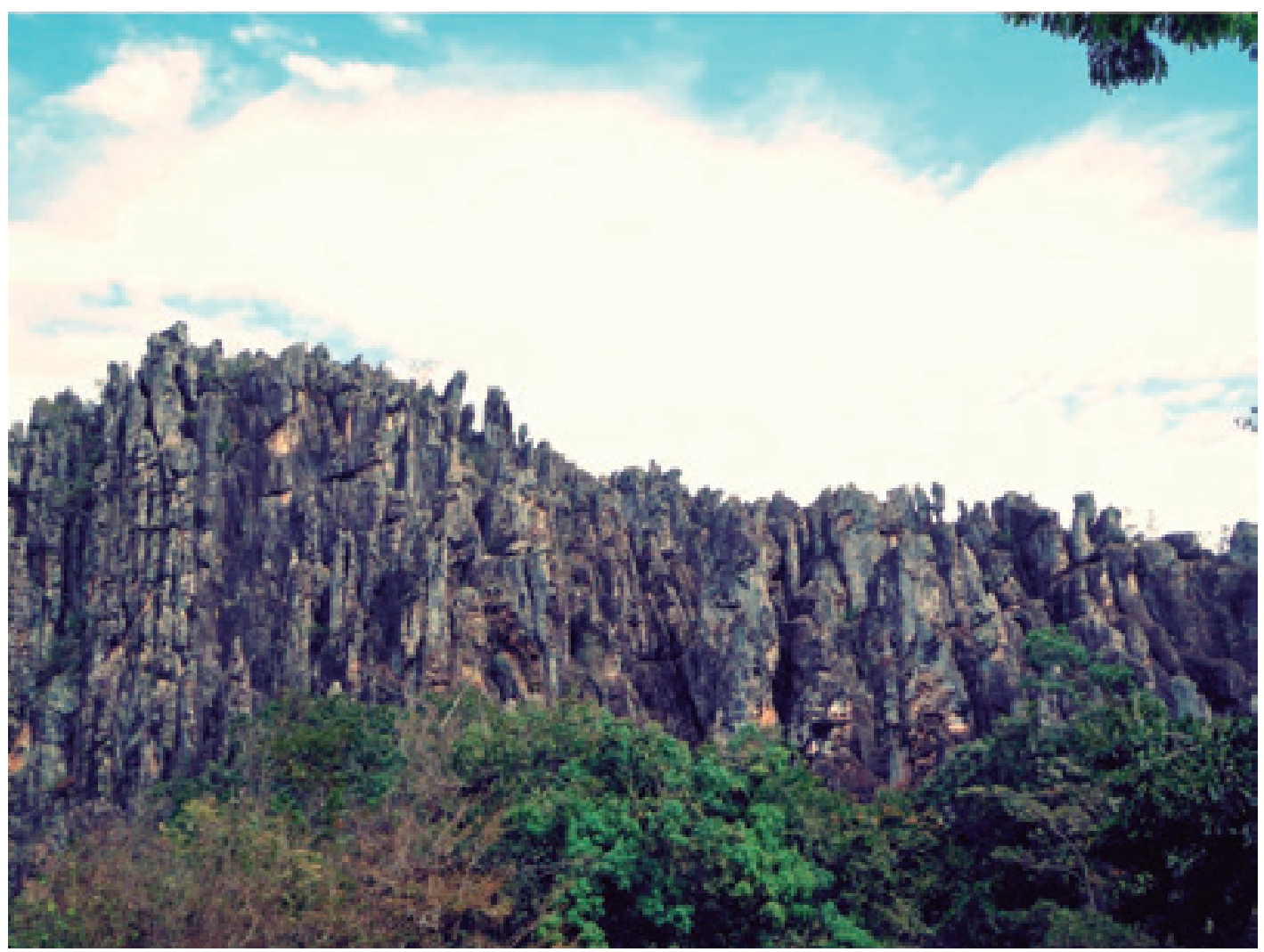

Figura 3. Gruta do Salitre

Fonte: Eveline R. Santos, 2014. 
A comunidade conta ainda com diversas manifestações culturais e religiosas. Dentre os principais eventos locais estão o "Carnaval Temporão de Curralinho", que corresponde a dois dias de festa no final de semana que antecede o início das comemorações oficiais do carnaval, e o "Festival de Arte e Cultura de Curralinho" que acontece todos os anos no mês de julho e, atualmente, se encontra em sua sétima edição.

Nos últimos anos, muitos moradores foram aos poucos abandonando suas residências e migrando para as grandes capitais do país em busca de melhores oportunidades. Diante disso, grande parte dos imóveis existentes em Curralinho foram adquiridos por moradores de Diamantina, que começaram a praticar o turismo de segunda residência na comunidade.

Enfim, todos esses atrativos somados a facilidade de acesso, têm contribuído para atrair um fluxo cada vez maior de visitantes para Curralinho, principalmente, nos finais de semana e feriados. O turismo, mais uma vez, está sendo estimulado pelos governantes como solução para reverter o cenário de estagnação socioeconômica de uma pequena comunidade. À vista disso, há uma dúvida que merece esclarecimento: "Qual a participação da população local no processo de desenvolvimento turístico?".

\section{O desenvolvimento do turismo em pequenas comunidades}

Entendemos que o turismo reflete grande importância, principalmente, do ponto de vista econômico, na geração de emprego e renda. No entanto, apesar dos benefícios advindos do desenvolvimento de tal atividade deve-se também considerar os malefícios, uma vez que, sem planejamento e uma boa gestão, a atividade turística pode afetar negativamente o local onde é introduzido.

Faz-se necessário, então, observar que turismo abrange muito mais que índices e números favoráveis à economia. A atividade turística envolve relações sociais, vivência de experiências enriquecedoras, valoração da paisagem, cultura e patrimônio local. Quando conduzido apenas em função de benefícios econômicos, a atividade acaba trazendo prejuízos para o ambiente onde se desenvolve (VIGNATI, 2008).

A respeito do desenvolvimento do turismo em uma comunidade, depara-se com o seguinte questionamento: O que a população local pensa ou espera do turismo? Apesar de já haver documentos que abordam a importância da participação da população local no processo de desenvolvimento do turismo em pequenas comunidades, estas referências ainda são poucas. Krippendorf (2001), afirma que a vasta documentação existente sobre o turismo apresenta abordagens e reflexões quase sempre centradas no turista ou nos interesses dos promotores do turismo. As interrogações se voltam para as im- 
pressões e comportamentos dos turistas, já que estes representam o mercado.

O turismo é uma atividade invasora e exigente e quando não debatida e analisada suficientemente, pode representar uma ameaça para a região onde é implementada. Ao lado dos resultados positivos, a atividade turística pode trazer também alguns efeitos negativos para as regiões receptoras e menos desenvolvidas. Estes riscos conduzem a criação de conflitos internos, a aceleração de uma aculturação dos jovens e enfraquecimento da coesão social (MALDONADO, 2009).

A vontade de superar a pobreza estimula as comunidades a buscar fontes alternativas de renda e a atividade turística é vista como uma saída para o desenvolvimento local. Contudo, pensar na introdução do turismo em uma comunidade requer planejamento

e, principalmente, a participação dos moradores, uma vez que direta ou indiretamente trata-se de uma intervenção nas práticas sociais locais (CORIOLANO, 2012).

Deste modo, o planejamento é a sistematização das ações e ordenamento das tarefas a serem realizadas, buscando estabelecer condições e prever caminhos favoráveis para alcançar os objetivos propostos. Planejar é prever possíveis desencontros ao longo da trajetória de realização das ações. O planejamento possibilita identificar as dificuldades que as organizações estão enfrentando ou irão enfrentar, criando alternativas para a superação destas. (RUSCHMANN, 2000).

Para Coriolano (2012), deve se pensar o desenvolvimento do turismo não apenas voltado à competitividade e o acúmulo de riquezas, mas para uma revolução de ideias e práticas sociais, que oriente pessoas e organizações para a produção partiIhada, respeitando os ciclos da natureza. Nesse sentido, a reflexão sobre desenvolvimento local vai além da proposta de melhoramento do sistema produtivo local. Beni (2006) afirma que o desenvolvimento visa atender as necessidades e demandas da população local por meio da participação ativa da comunidade envolvida, buscando bem estar social, econômico e cultural da mesma.

Embora sejam diversas as preocupações para garantir o desenvolvimento da atividade turística de forma organizada, observa-se que as comunidades ainda apresentam certas dificuldades de compreensão do turismo, considerando não apenas as benfeitorias advindas, mas também os fatores indesejáveis.

\section{Percepção do turismo pela comunidade local}

Ramalho e Sarmento (2004) apontam que, tratar o turismo a partir do lugar e de sua identidade demanda uma abordagem de valores significativos e aspectos relevantes na conjuntura em que se convive com turismo, principalmente no que 
se refere aos processos globais. Para tanto, discutir a percepção do lugar tanto na concepção dos moradores quanto dos turistas também requer uma análise mais apurada do contexto em que cada um se insere.

Dessa forma, entender e diagnosticar a percepção dos moradores locais em relação à comunidade e ao turismo nela desenvolvido se faz necessário como forma de compreender a posição e as reflexões que estes fazem em relação à atividade turística local.

O turismo tem o espaço ou lugar como componente fundamental para a concretização da atividade. Os termos "espaço" e "lugar" ao mesmo tempo em que são familiares e indicam experiências em comum diferem entre si. Tuan (1983) descreve a noção de espaço como algo abstrato e ligado a liberdade, enquanto que o lugar se une a noção de segurança juntamente com o simbolismo e sentimentos proporcionados pelas experiências e vivências.

No decorrer de nossas experiências, o significado de espaço se funde com o de lugar. Vivenciamos experiências diretas e íntimas em um determinado espaço, conhecendo-o melhor, envolvendo sentimentos e dotando-o de valor simbólico e conceitual, assim este espaço adquire o sentido de "lugar". Lugares são, portanto, centros aos quais atribuímos valor ou um conjunto de significados refletidos da experiência e aspirações humanas (TUAN, 1983).

A percepção do lugar pelos indivíduos faz parte da sua experiência e afinidade com o espaço que o circunda, incluindo fatos atuais, lembranças recentes ou passadas (TUAN, 1983). É por meio das vivencias e das lembranças que os moradores locais irão atribuir significados e valores à comunidade e ao turismo nela desenvolvido.

Sendo assim, entende-se por percepção a compreensão de fatos, formação de ideias e a obtenção de conhecimento por meio dos sentidos. A percepção é o ato ou efeito de perceber o que acontece em nosso entorno e está se dá por meio da integração entre os sentidos, da visualização, da observação do comportamento dos indivíduos e dos diversos elementos que compõem esse campo e sensitivo e visual.

Logo, pode-se afirmar que a percepção e/ou conhecimento do lugar e de seus elementos faz parte da experiência do indivíduo, e é por meio desta experiência que cada um atribuirá significados e valores ao lugar.

\section{Resultados e discussões}

Considerando que a participação da comunidade no processo de desenvolvimento do turismo é extremamente necessária para que a atividade seja viável e sustentável 
ao longo do tempo, ainda que encontre condições desfavoráveis, buscou-se identificar a visão dos moradores sobre a importância do turismo para Curralinho, e os impactos causados pelo desenvolvimento da atividade turística na comunidade.

A pesquisa realizada permitiu primeiramente identificar, por meio da interpretação dos dados coletados, o perfil socioeconômico dos moradores entrevistados. Essa informação é importante para pressupor uma ideia geral da realidade da comunidade. Neste sentido, observou-se que dos 42 moradores de Curralinho que se dispuseram a responder o questionário 29 (69\%) eram homens, e $13(31 \%)$ mulheres. Quanto à faixa etária, 15 (36\%) tinham idade entre 20 a 30 anos, 13 (31\%) entre 31 e 40 anos, 5 (12\%) entre 41 a 50 anos, 5 (12\%) entre 51 e 60 anos, e 4 (9\%) tinham acima de 60 anos.

Inicialmente, a constatação que atraiu mais a atenção foi o baixo nível de escolaridade dos entrevistados, sendo que 12 (29\%) possuem ensino médio completo, 8 (19\%) o ensino fundamental completo, 14 (33\%) o ensino fundamental incompleto, 2 (5\%) declararam-se analfabetos, $3(7 \%)$ possuem o ensino superior completo incompleto, e apenas 1 (2\%) possuem o ensino superior completo.

A falta de qualificação da mão-de-obra local de Curralinho reflete diretamente nas atividades remuneradas exercidas pelos moradores e, por conseguinte, na renda mensal das famílias. A respeito da profissão, $8(19 \%)$ dos entrevistados declararam que são domésticas em suas próprias casas ou de outras famílias, 6 (14\%) garimpeiros, $4(10 \%)$ pedreiros, $3(7 \%)$ aposentados, 2 (5\%) vigilantes, e 4 (10\%) estão desempregados. Com relação a renda mensal familiar, 54 (57\%) sobrevivem com até 1 salário mínimo, $15(36 \%)$ até 2 salários, e $3(7 \%)$ até 3 salários.

Esses dados confirmam a estagnação socioeconômica que, atualmente, enfrenta a comunidade de Curralinho. Segundo Araujo (2014), há pouca oferta de trabalho e renda para os moradores locais, o que faz com que muitos abandonem suas casas para ir buscar melhores condições de vida nos grandes centros urbanos. Outra fato que merece ser destacado é a permanência da atividade garimpeira na comunidade como uma das principais fontes de renda, mesmo com o rigor da legislação ambiental vigente no país.

Quanto ao tempo de residência na comunidade verificou-se que 21 (50\%) dos entrevistados moram em Curralinho desde que nasceram, e 16 (38\%) residem na comunidade a mais de 20 anos. Esse resultado já era previsto, visto que muitos dos moradores apesar de saírem para trabalhar em outras regiões acabam voltando, constituindo uma família e continuando vivendo na comunidade.

Sabendo que o turismo corresponde a uma atividade que não se mantém por si só, ou por esforços de terceiros, pois o desejo de se inserir no setor turístico deve partir da própria comunidade (VIGNATI, 2008; RUSCHMANN, 2000), buscou-se 
compreender a visão, os anseios e as angústias dos moradores de Curralinho com relação ao turismo na comunidade. Verificou-se que 35 (85\%) dos entrevistados veem o turismo como uma importante alternativa de desenvolvimento socioeconômico. Para eles, o turismo pode contribuir para melhoria da qualidade de vida, especialmente, através da geração de emprego e renda.

Porém, 23 (55\%) dos entrevistados acredita que a atividade turística ainda não tem possibilitado benefícios financeiros efetivos para as famílias. Atualmente, existem moradores da comunidade que complementam a sua renda por meio do turismo, mas estes beneficiados em sua maioria são jovens que realizam trabalhos temporários durante eventos que acontecem esporadicamente, principalmente, na Gruta do Salitre. Neste sentido, ainda que o turismo, atualmente, não represente um setor relevante para complementação de renda das famílias locais, essas acreditam que isso poderá vir acontecer quando for maior o fluxo de visitantes na comunidade.

Considerando importância do envolvimento dos moradores locais no processo de desenvolvimento do turismo na comunidade, foi questionado sobre o interesse dos mesmos de participarem de uma associação local preocupada com o planejamento e monitoramento das atividades turísticas. A maior parte dos moradores entrevistados (49\%) demonstrou interesse em contribuir com desenvolvimento do turismo local. Sendo que, alguns desses moradores já participaram, ou participam da associação comunitária que existe em Curralinho. Contudo, alguns moradores (20\%) ressaltaram que participariam de uma associação somente se percebessem que realmente traria resultados positivos. Isso acontece, porque muitos já se envolveram em iniciativas isoladas em prol do desenvolvimento turístico local, que não tiverem sequência após ocorrerem mudanças de gestão política municipal. Constatou-se durante as entrevistas que essas frustrações geraram desânimo e descrença em boa parte da população local.

Outro ponto importante levantado através das entrevistas refere-se a participação ativa dos moradores locais nas atividades que acontece na comunidade e como estes podem contribuir para a melhoria do turismo na comunidade. Neste sentido, 20 (49\%) dos moradores afirmaram que poderiam contribuir com o turismo na comunidade, sendo solícitos com os visitantes e/ou prestando serviços de condutores. Todavia, observou-se que a comunidade sente a necessidade de se capacitar para saber lidar melhor com o visitante e, consequentemente, contribuir para a melhoria do turismo local. Os moradores ressaltaram que falta alguém que os orientem sobre como funciona o turismo e o que pode ser feito para desenvolvê-lo de forma adequada. Essa necessidade gera a demanda por cursos de capacitações. 
Com relação aos impactos do turismo, buscou-se compreender a percepção dos moradores locais sobre os benefícios e malefícios que as atividades turísticas geram para a comunidade. Considerando a conduta das pessoas que, atualmente, visitam a comunidade de Curralinho, observou-se que apesar da grande maioria dos entrevistados (69\%) afirmarem que o comportamento dos turistas não incomoda os moradores locais, uma pequena parcela (7\%) se diz insatisfeita, principalmente quanto ao barulho produzido pelos visitantes. Neste ponto, destaca-se o som automotivo extremamente alto recorrente nas ruas de Curralinho durante os finais de semana e feriados, e as festas particulares que ocorrem, principalmente, em casas alugadas para esse fim.

Sobre o consumo de drogas na comunidade a maior parte dos moradores (54\%) acredita que o turismo não contribui para isso. Contudo, $22 \%$ dos entrevistados afirma que o turismo pode influenciar e, por isso merece uma atenção maior por parte da população local e dos governantes para implementarem programas de prevenção. Por meio das observações feitas na comunidade, principalmente, em eventos que atraem um grande número de visitantes como, por exemplo, o Carnaval Temporão de Curralinho, pode-se perceber que esta afirmação tem fundamento. $\mathrm{O}$ uso de bebidas alcoólicas e outros tipos de drogas ilícitas acontecem livremente, o que acaba contribuindo para ocorrência de conflitos entre as pessoas.

Quanto a alterações dos costumes antigos e hábitos da comunidade por influência do turismo é interessante perceber que se ocorreu alguma mudança, estas não foram muito relevantes, uma vez que a maioria dos moradores entrevistados (84\%) afirmou não ter percebido alterações. Destaca-se nesse ponto a importância do turismo como uma ferramenta que deve facilitar o desenvolvimento local, porém fortalecendo a identidade e as particularidades do lugar.

Com relação à influência do turismo na preservação do patrimônio cultural e natural da comunidade. Constatou-se que a maioria dos moradores entrevistados (67\%) acredita que o turismo contribui para a conservação do patrimônio local. Porém, alguns (21\%) afirmaram que a atividade turística não tem sido relevante para preservação do patrimônio da comunidade de Curralinho. Isso ocorre pelo fato de alguns moradores considerarem o cenário criado para as gravações da novela "Irmãos Coragem" da Rede Globo, em 1995, como parte de seu patrimônio e da identidade local que deveria ser preservado. Todavia, atualmente, boa parte desse cenário se encontra em ruínas, como por exemplo a fictícia "Delegacia de Corado".

Por fim, buscou-se analisar a influência no aumento dos preços de produtos e serviços na comunidade em função do turismo. Para $48 \%$ dos moradores entrevistados o turismo não exerce significativa influência no aumento do preço dos produtos. 
No entanto, segundo $62 \%$ dos entrevistados, o turismo contribuiu para o aumento do preço da mão de obra local, e $79 \%$ acredita que o turismo refletiu na valoração imobiliária dos terrenos e habitações.

Apesar disso, os autores acreditam que aumento dos preços dos imóveis e da mão-de-obra local em Curralinho, não é reflexo da atividade turística que atualmente ocorre por lá, mas do crescimento populacional que vem acontecendo em Diamantina nos últimos anos e, consequentemente, a valorização dos imóveis no núcleo urbano dessa cidade. Logo, as pessoas passaram enxergar os distritos, assim como Curralinho, como locais alternativos para se viver, pois oferecem um ambiente tranquilo e um custo de vida mais baixo. A proximidade de Curralinho, somada a possibilidade de em breve pavimentarem a estrada que dá acesso a comunidade fez com que muitas pessoas cogitassem a possibilidade de se mudarem pra lá, em decorrência disso, ocorreu uma valorização dos imóveis e terrenos da comunidade. Além disso, o aumento salarial e a inflação colaboraram para o aumento do preço da mão de obra não apenas na comunidade, mas em todo o país, ainda que esse aumento seja pequeno em relação ao que é pago em outros lugares.

\section{Considerações finais}

Apesar do turismo ser considerado uma das principais atividades econômicas da atualidade, há tempos existe uma preocupação por parte dos pesquisadores da área em controlar as formas de desenvolvimento das atividades turísticas. Nota-se que esta preocupação se volta, principalmente, para as pequenas comunidades onde o turismo é incentivado, como é o caso de Curralinho. A participação da comunidade nos processos de desenvolvimento do turismo é fundamental, uma vez que são os moradores locais quem devem ditar o tipo de turismo que querem para sua comunidade.

Pode-se perceber através desse estudo que os moradores de Curralinho têm interesse em participar do processo de desenvolvimento turístico da comunidade. Todavia, a falta de integração dos moradores foi apresentada como um dos principais empecilhos. Ficou nítido na fala dos entrevistados a necessidade de união e participação de todos os moradores locais no desenvolvimento turístico local, bem como, a necessidade de capacitação e qualificação para lidar com a atividade.

A relação dos visitantes com os moradores locais aparentemente é harmônica, no entanto são poucos os moradores que realmente interagem com os visitantes. No que diz respeito aos aspectos negativos, um dos mais ressaltados tanto nos diálo- 
gos com os moradores quanto nas observações diretas feitas na comunidade, foi a questão do barulho provocado por sons automotivos.

Verificou-se ainda que os moradores locais sentem a necessidade da melhoria das vias de acesso e de maior divulgação da comunidade como destino turístico. De acordo com a percepção dos moradores, estes dois fatores aliados à participação efetiva da comunidade, a capacitação e qualificação dos moradores, e a melhoria da infraestrutura local é que promoverão melhorias para o turismo na comunidade.

Com base nos dados e discussões apresentados espera-se que os resultados alcançados contribuam para uma intervenção dos órgãos públicos e associações em prol do desenvolvimento local, no sentido de se criar um planejamento turístico adequado a realidade local, considerando as percepções e participação dos moradores locais em todo o processo. Curralinho é uma comunidade com um potencial turístico que precisa apenas ser trabalhado de forma adequada para contribuir com a melhoria da qualidade de vida dos moradores locais.

\section{Referências}

ARAUJO, Hugo Rodrigues. Valoração dos serviços ambientais da Gruta do Salitre, Diamantina/MG. 2014. 72f. Dissertação (Mestrado em Sustentabilidade Socioeconômica Ambiental - Núcleo de Pesquisas e Pós-Graduação em Recursos Hídricos, Universidade Federal de Ouro Preto, Ouro Preto, 2014.

AZEVEDO, Alexsander Araujo; ARAUJO, Hugo Rodrigues. Processo de Estruturação da Gestão do Uso Público da Gruta do Salitre, Diamantina, Minas Gerais. In: Congresso Brasileiro de Espeleologia, 31., 2011, Ponta Grossa-PR. Anais eletrônico... Disponível em: <http://www.sbe.com.br/anais31cbe/31cbe_201-208.pdf>. Acesso em: 28/04/2014.

BENI, Mário Carlos. Política e planejamento de turismo no Brasil. São Paulo: Aleph, 2006.

BRASIL. Ministério do Turismo. Dinâmica e diversidade do turismo de base comunitária: desafio para a formulação de política pública. Brasília: Ministério do Turismo, 2010. Disponível em: <http://www.turismo.gov.br/export/sites/default/turismo/o_ ministerio/publicacoes/downloads_publicacoes/Caderno_MTur_alta_res.pdf >. Acesso em: 15/01/2014.

CORIOLANO, Luzia Neide. A Contribuição do Turismo ao Desenvolvimento Local. In: PORTUGUEZ, A. P.; SEABRA, G. F., QUEIROZ, O. T. M. M. (Org). Turismo, espaço e estratégias de desenvolvimento local. João Pessoa: UFPB, 2012. 
DIAMANTINA. Secretaria Municipal de Cultura, Turismo e Patrimônio de Diamantina. Patrimônio, turismo e artesanato no distrito de Extração/ Curralinho. Diamantina, 2004. HERKENHOFF, Mônica; BORGES, Izabel. Plano Diretor Participativo do Município de Diamantina/MG - Documento Técnico. Vol. 1. TECHNUN Consultoria, 2009.

IBGE - INSTITUTO BRASILEIRO DE GEOGRAFIA E ESTATÍSTICA. Pesquisa de Informações Básicas Municipais. Rio de Janeiro: IBGE, 2010.

KRIPPENDORF, Jost. Sociologia do turismo: para uma nova compreensão do lazer e das viagens. São Paulo: Aleph. 2001.

MALDONADO, Carlos. O turismo rural comunitário na América Latina: gênesis, características e políticas. In: BARTHOLO, Roberto et al (Orgs). Turismo de base Comunitária: diversidade de olhares e experiências brasileiras. Rio de Janeiro: Letra e Imagem, 2009.

MATTAR, F. Pesquisa de Marketing. 5. Ed. Rio de Janeiro: Elsevier, 2012.

MINAS GERAIS. Secretaria de Estado de Turismo. Inventário da Oferta Turística- Categoria: Informações Básicas Dos Distritos. Belo Horizonte, 2002. Disponível em: <http:// www.bnb.gov.br/content/aplicacao/prodetur/downloads/docs/mg_7_2_inventario_ oferta_turistica_informac_basica_distrito_100708.pdf>. Acesso em: 15/01/14.

PANOSSO NETTO, Alexandre; TRIGO, Luiz Gonzaga Godoi. Cenários do turismo brasileiro. São Paulo: Aleph, 2009.

RAMALHO FILHO, Rodrigo; SARMENTO, Maria Emília C. Turismo, Lugar e Identidade. Revista Licerce, Belo Horizonte, v.7, n.1, p.35-46, 2004.

RUSCHMANN, Doris Van de Meene. Turismo e Planejamento Sustentável. Campinas: Papirus. 2000.

TUAN, Yi-Fu. Espaço e lugar: a perspectiva da experiência. São Paulo: DIFEL, 1983. VIGNATI, Federico. Gestão de destinos turísticos: como atrair pessoas para pólos, cidades e países. Rio de Janeiro: SENAC, 2008. 